\title{
Metabolic Response to Submaximal and Maximal Exercise in People with Severe Obesity, Prediabetes, and Diabetes
}

\author{
Francesca Battista $^{a, b}$ Anna Belligoli ${ }^{b, c}$ Daniel Neunhaeuserer ${ }^{a, b}$ \\ Andrea Gasperetti ${ }^{a, b}$ Silvia Bettini ${ }^{b, c}$ Chiara Compagnin ${ }^{b, c}$ \\ Riccardo Marchese ${ }^{b, c}$ Giulia Quinto ${ }^{a, b}$ Marco Bergamin ${ }^{a, b}$ Roberto Vettor ${ }^{b, c}$ \\ Luca Busetto $^{\mathrm{b}, \mathrm{c}}$ Andrea Ermolao ${ }^{\mathrm{a}, \mathrm{b}}$ \\ ${ }^{a}$ Sports and Exercise Medicine Division, Department of Medicine, University of Padova, Padova, Italy; ${ }^{\mathrm{b} C e n t e r}$ for the \\ Study and the Integrated Treatment of Obesity, Padova Hospital, Padova, Italy; 'Department of Medicine, Internal \\ Medicine 3, University Hospital of Padova, Padova, Italy
}

\section{Keywords}

Cardiopulmonary exercise test $\cdot$ Functional evaluation .

Metabolic flexibility · Morbid obesity $\cdot$ Respiratory

Exchange Ratio

\begin{abstract}
Introduction: Metabolic adaptations to maximal physical exercise in people with obesity ( $\mathrm{PwO}$ ) are scarcely described. This cross-sectional study evaluates the metabolic response to exercise via the respiratory exchange ratio (RER) in PwO and different degrees of glycemic control. Methods: Eightyfive PwO (body mass index 46.0 [39.0-54.0] kg/m²), that is, 32 normoglycemic (Ob-N), 25 prediabetic (Ob-preDM), and 28 diabetic (Ob-T2DM) subjects and 18 healthy subjects performed an incremental, maximal cardiopulmonary exercise test. The RER was measured at rest (RERrest) and at peak exercise (RERpeak). Results: RERpeak was significantly higher in healthy subjects than that in PwO. Among those, RERpeak was significantly higher in Ob-N than that in Ob-preDM and Ob-T2DM (1.20 [1.15-1.27] vs. 1.18 [1.10-1.22] $p=0.04$ and vs. 1.14 [1.10-1.18] $p<0.001$, respectively). Accordingly,
\end{abstract}

karger@karger.com www.karger.com/ofa

Karger $\stackrel{\text { ' }}{5}$

BOPEN ACCESS
(C) 2021 The Author(s)

Published by S. Karger AG, Basel

This is an Open Access article licensed under the Creative Commons Attribution-NonCommercial-4.0 International License (CC BY-NC) (http://www.karger.com/Services/OpenAccessLicense), applicable to the online version of the article only. Usage and distribution for commercial purposes requires written permission. $\triangle$ RER (RERpeak-RERrest) was lower in Ob-preDM and ObT2DM than that in Ob-N $(0.32$ [0.26-0.39] $p=0.04$ and 0.29 [0.24-0.36] $p<0.001$ vs. 0.38 [0.32-0.43], respectively), while no significant difference was found in $\triangle R E R$ between ObpreDM and Ob-T2DM and not even between Ob-N and healthy subjects. Moreover, $\triangle \mathrm{RER}$ in PwO correlated with glucose area under curve $(p=0.002)$. Conclusions: PwO demonstrate restricted metabolic response during maximal exercise. Particularly, those with prediabetes already show metabolic inflexibility during exercise, similarly to those with type 2 diabetes. These findings also suggest a potential role of cardiopulmonary exercise testing in detecting early metabolic alterations in PwO.

(c) 2021 The Author(s).

Published by S. Karger AG, Basel

\section{Introduction}

Severe obesity is a disease tightly associated with metabolic syndrome, cardiovascular events, and all-cause mortality $[1,2]$. The obesity epidemic is constantly expanding at all ages, due to a widespread lifestyle based on 
sedentary habits and overfeeding [3]. The energy surplus stemming basically from physical inactivity and excessive caloric intake induces profound changes in metabolic pathways and raises the risk of type 2 diabetes. The natural history of the onset of type 2 diabetes, especially in people with obesity, involves different metabolic steps of impairment of glucose metabolism and metabolic flexibility $[2,4]$. Indeed, metabolic flexibility is a pathophysiological concept concerning the capacity of shifting fuel selection in response to different metabolic requests (e.g., fasting, food intake, insulin stimulation) [5] and, in resting conditions, it can be assessed by indirect calorimetry [6]. Although metabolic flexibility becomes even more important during physical exercise to couple the substrate availability with the increasing metabolic demands, this has only been partially investigated in subjects affected by type 2 diabetes and obesity, and even less in those with prediabetes [5]. In people with obesity $(\mathrm{PwO})$, it has been shown that already prediabetes is associated with early target organ damage, increased cardiovascular risk [7], and morphological modifications of their adipose tissue [8]. However, this condition has not been extensively studied since it is still frequently considered an initial stage of diabetes and not as disease itself. Subjects' substrate utilization and the associated metabolic response to physical exercise can be examined by cardiopulmonary exercise testing (CPET), which is also the gold standard test for the assessment of cardiorespiratory fitness, a strong prognostic marker, both for cardiovascular and all-cause mortality [9]. CPET is a noninvasive technique that relies primarily on the measurement of minute ventilation, oxygen consumption $\left(\mathrm{VO}_{2}\right)$ and carbon dioxide production $\left(\mathrm{VCO}_{2}\right)$ during exercise $[10,11]$. The thereby registered respiratory exchange ratio (RER), simply calculated as $\mathrm{VCO}_{2} / \mathrm{VO}_{2}$, not only indicates subjects' efforts and exercise intensities but also reflects the energy substrate utilization. When RER is low, fats represent the primary fuel for exercise, but with increasing intensity, the energy is mainly supplied by glucose resulting in higher RER values [12]. Indeed, the RER may represent an interesting noninvasive functional marker of metabolic adaptations and (in)flexibility during exercise, which could be useful also in clinical settings where CPET should be regularly performed [13]. Thus, the aim of this study was to investigate the metabolic response to incremental exercise in people with severe obesity and different degree of metabolic impairment.

\section{Methods}

\section{Experimental Design and Participants}

This is an observational cross-sectional study conducted in 85 $\mathrm{PwO}$ and 18 age- and gender-matched healthy subjects (HS) included as controls. Participants were consecutively recruited at the Centre for the Study and Integrated Treatment of Obesity of the Padua University Hospital between January 2014 and October 2019. PwO eligible for this study had a body mass index (BMI) $\geq 35$ $\mathrm{kg} / \mathrm{m}^{2}$ with obesity-related comorbidities or a BMI $\geq 40 \mathrm{~kg} / \mathrm{m}^{2}$ with or without comorbidities, while the inclusion criteria for the HS were a $\mathrm{BMI}<30 \mathrm{~kg} / \mathrm{m}^{2}$ and a normal fasting glucose level. Patients with cancer, chronic inflammatory diseases, drugs or alcohol abuse were excluded. The prevalence of the 3 principal obesityrelated comorbidities (hypertension, dyslipidemia, and obstructive sleep apnea syndrome) was calculated on the basis of international criteria [14-16]. Each included participant provided written informed consent. The study has been performed in accordance with the principles of the Declaration of Helsinki (revised in 2008) and is presented following the STROBE checklist (see online suppl. Table 1; see www.karger.com/doi/10.1159/000517589 for all online suppl. material). The protocol was approved by the "Padua Ethical Committee for Clinical Research" (2892P, June 10, 2013).

\section{Measurements}

Each PwO underwent complete blood biochemical analyses after an 8-h fasting period, determining fasting plasma glucose (FPG), insulin, lipid profile, high-sensitivity C-reactive protein, interleukin-6, and leptin levels. Moreover, a 3-h 75 g oral glucose tolerance test was performed, measuring blood glucose and insulin plasma levels at baseline and 30, 90, 120, 150, and 180 min after glucose loading $(180 \mathrm{~mL}$ of syrup with 82.5 g glucose monohydrate equal to $75 \mathrm{~g}$ of glucose). The oral glucose tolerance test was not performed in subjects with previous diagnosis of type 2 diabetes. Biochemical measurements were performed using diagnostic kits standardized according to the World Health Organization First International Reference Standard, as described in previous studies [8]. Insulin sensitivity and insulin resistance indices were calculated through the Matsuda index and the Homeostasis Model Assessment index $\left(\mathrm{HOMA}_{\mathrm{IR}}\right)$, respectively $[17,18]$. Moreover, the areas under the curve for glucose and insulin $\left(G_{\mathrm{AUC}}\right.$ and $\left.I_{\mathrm{AUC}}\right)$ were calculated using the trapezoidal method. In accordance with the American Diabetes Association, $\mathrm{PwO}$ were divided into 3 groups depending on their glycemic profile, that is normoglycemic (Ob$\mathrm{N}$ ), prediabetic (Ob-preDM), and diabetic (Ob-T2DM) PwO [7]. In subjects with type 2 diabetes, glycated hemoglobin $\mathrm{A}_{1 \mathrm{c}}\left(\mathrm{Hb}_{1 \mathrm{c}}\right)$ was evaluated by high-performance liquid chromatography. Indirect calorimetry was performed in fasting condition and after 15 min of rest in a comfortable and thermo-neutral environment. A ventilated canopy calorimeter was used (Vmax; Sensormedics, Milan, Italy). $\mathrm{VO}_{2}$ and $\mathrm{VCO}_{2}$ were measured continuously, and values were averaged in 1-min intervals. Fasting RER (RERfast) was calculated by using the Weir [19] equation. Consecutively, body composition was analyzed by a single-frequency $(300 \mu \mathrm{A}, 50 \mathrm{kHz})$ electrical impedance analyzer (Soft Tissue Analyzer; Akern, Pontassieve, Italy). Moreover, the skeletal muscle mass (SM) was calculated using the equation proposed by Janssen et al. [20]: SM (kg) $=[(\mathrm{Ht} 2 / \mathrm{R} \times 0.401)+($ gender $\times 3.825)+($ age $\times-0.071)]+5.102$. Maximal isometric handgrip strength tests were performed 3 times for each hand, using a calibrated dynamometer (Baseline, Elms- 


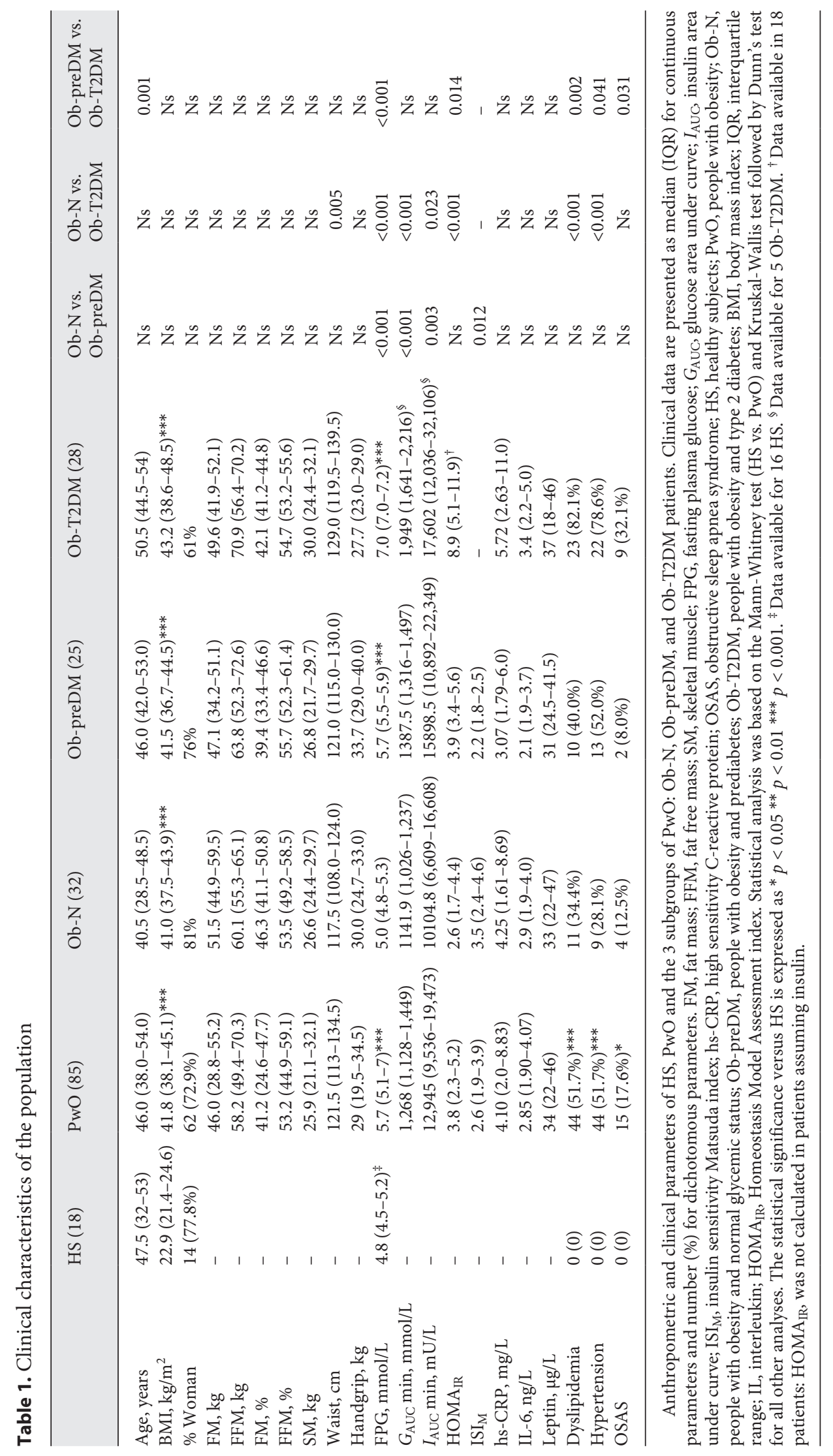


ford, NY, USA) and taking the average value for analysis. ECGmonitored CPET was performed on a treadmill or in a small minority on a cycle ergometer, depending on the subjects' clinical characteristics. Ventilatory parameters were sampled breath by breath with the Jaeger-Masterscreen-CPX (Carefusion). The incremental modified Bruce ramp protocol was used for treadmill testing, while a 15-Watts/min ramp protocol was used on cycle ergometer [21]. Peak oxygen consumption $\left(\mathrm{VO}_{2}\right.$ peak) and the oxygen uptake efficiency slope were determined as markers of aerobic exercise capacity. All tests were performed until subjects' exhaustion. Maximal effort was defined as a RER of at least 1.10 [10], and/or a maximal heart rate of $\geq 85 \%$ of predicted by age, and/or a Borg rating of perceived exertion $\geq 18 / 20$ [22]. All people who did not reach the indicated criteria were excluded from the study. Functional exercise capacity was measured as metabolic equivalent of tasks (METs). The RER determined during CPET was measured at rest (RERrest), after achieving stable breathing conditions, and throughout the test until reaching peak exercise (RERpeak). The RER at submaximal intensity $\left(\mathrm{RER}_{\mathrm{AT}}\right)$ was determined by the mean of the RER values recorded 1 min before the anaerobic threshold. RER variations during exercise were calculated as RERpeak-RERrest $(\triangle R E R)$ and as a percentage of increase $(\triangle R E R \%)$ in order to correct for baseline.

\section{Statistical Analyses}

Median values with interquartile range, and percentages were used to describe the continuous and dichotomous clinical parameters, respectively. All variables were tested for normality using the Shapiro-Wilk test and, based on their distribution, intergroup comparisons were performed by a parametric one-way ANOVA followed by Bonferroni post hoc analysis or nonparametric Kruskal-Wallis test followed by the Dunn's multiple comparison post hoc test. Student's $t$ test or the Mann-Whitney test was used when 2 groups were compared. Pearson's $\chi^{2}$ test was used to compare dichotomous variables. Two-sided $p$ values $<0.05$ were considered statistically significant. Pearson's correlation coefficient $(r)$ and the respective $p$ value were calculated to analyze correlations between variables. Multivariate stepwise regression analysis was performed to establish independent determinants. Statistical analyses were performed using Statistical Package for Social Science 20 (SPSS Inc., Chicago, IL, USA).

\section{Results}

\section{Clinical Characteristics of Study Population}

Demographic and anthropometric characteristics of the population are described in Table 1 . Among all included $\mathrm{PwO}, 32$ were $\mathrm{Ob}-\mathrm{N}, 25 \mathrm{Ob}-\mathrm{preDM}$, and $28 \mathrm{Ob}-$ T2DM. The prevalence of comorbidities progressively increased in the 3 groups of $\mathrm{PwO}$ and $\mathrm{Ob}-\mathrm{T} 2 \mathrm{DM}$ groups displayed the highest percentage of subjects affected by hypertension and dyslipidemia. Inflammatory cytokines showed no substantial difference between the 3 groups of PwO. Furthermore, PwO were mostly sedentary (80.7\%) without significant differences among subgroups (Ob-N
$=81.3 \%$; Ob-preDM $=79.2 \%$; Ob-T2DM $=81.5 \%)$. In $\mathrm{PwO}, \mathrm{CPET}$ was mostly performed on a treadmill (89.4\%), however, $11.6 \%$ were tested on a cycle ergometer with a similar subgroup distribution.

\section{Metabolic Profile and Body Composition}

$\mathrm{HOMA}_{\text {IR }}$ was higher in Ob-T2DM subjects than both Ob-N $(p<0.001)$ and Ob-preDM $(p=0.014)$, whereas it was not significantly different between $\mathrm{Ob}-\mathrm{N}$ and $\mathrm{Ob}$ preDM. However, $G_{\mathrm{AUC}}, I_{\mathrm{AUC}}$, and insulin sensitivity Matsuda index highlighted significant differences between $\mathrm{Ob}-\mathrm{N}$ and $\mathrm{Ob}$-preDM or Ob-T2DM subjects (Table 1). Fifty-two percent of the Ob-preDM subjects had impaired FPG, 24\% had impaired glucose tolerance, and $24 \%$ had both. More than half (68\%) of Ob-T2DM subjects had a diagnosis established $<5$ years ago. Moreover, $29 \%$ had a poor diabetes control $\left(\mathrm{HbA}_{1 \mathrm{c}}\right.$ higher than 69 $\mathrm{mmol} / \mathrm{mol}$ ), while $40 \%$ had an $\mathrm{HbA}_{1 \mathrm{c}}$ level lower than 59 $\mathrm{mmol} / \mathrm{mol}$ (in $20 \%$ of Ob-T2DM subjects $\mathrm{HbA}_{1 \mathrm{c}}$ levels were not available). Microalbuminuria was detectable in $6(21 \%)$ Ob-T2DM subjects, microvascular damage in 3 (10.7\%) Ob-T2DM subjects and macrovascular damage only in $1(3.6 \%)$ Ob-T2DM subject. No significant differences in fat mass (FM), fat free mass (FFM), and SM were observed among the 3 groups of $\mathrm{PwO}$ (Table 1). Last, handgrip strength was also similar in the 3 subgroups of $\mathrm{PwO}$ (Table 1$)$ and significantly correlated with FFM ( $r=$ 0.547, $p=0.001)$.

\section{CPET}

$\mathrm{PwO}$ showed significantly lower exercise tolerance than HS, as well as lower submaximal and maximal aerobic capacity (METs, $\mathrm{VO}_{2} \mathrm{AT}$, and $\mathrm{VO}_{2}$ peak $/ \mathrm{kg}$, respectively; all $p<0.001)$. No difference was found in absolute aerobic power (Table 2). Among $\mathrm{PwO}, \mathrm{Ob}-\mathrm{T} 2 \mathrm{DM}$ had lower exercise tolerance (METs) than Ob-preDM ( $p=$ $0.039)$ and $\mathrm{Ob}-\mathrm{N}(p=0.024)$, but no difference was found between $\mathrm{Ob}-$ preDM and $\mathrm{Ob}-\mathrm{N}$. Moreover, functional capacity expressed as $\mathrm{VO}_{2}$ peak $/ \mathrm{kg}$ followed the same trend, showing indeed similar outcomes between Ob-preDM and $\mathrm{Ob}-\mathrm{N}$. Regarding the metabolic response to exercise, data showed similar RERfast, RERrest, and RER $_{\text {AT }}$ when people with and without obesity were compared, while RERpeak and the variation from rest to peak were significantly higher in HS than in $\mathrm{PwO}(p<0.001)$. Moreover, RERpeak was significantly higher in Ob-N than both Ob-preDM and Ob-T2DM ( $p=0.04$ and $p=0.001$, respectively). Accordingly, when analyzing $\triangle$ RER from rest to peak exercise, $\mathrm{Ob}-\mathrm{N}$ showed a significantly greater increase in RER than Ob-preDM $(p=0.04)$ and Ob- 


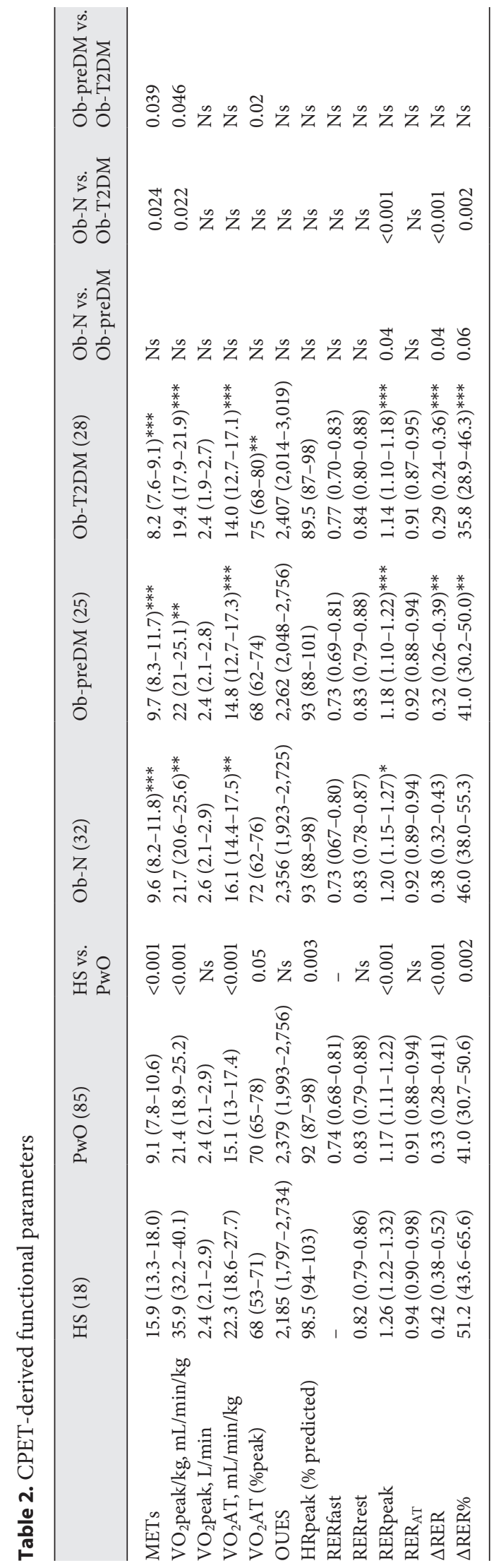

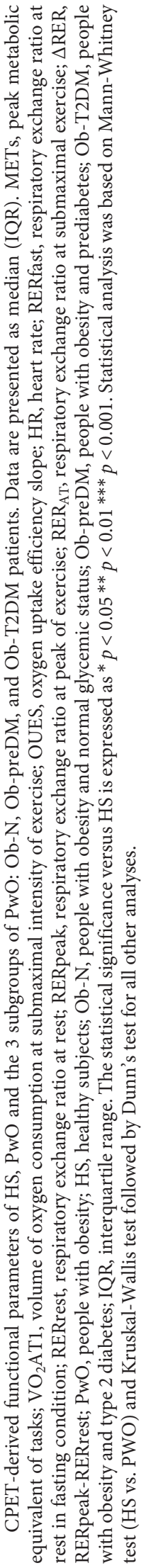

T2DM $(p<0.001)$, respectively (Fig. 1). Data further showed that $\triangle$ RER and $\triangle$ RER\% were neither significantly different between Ob-preDM and Ob-T2DM nor between $\mathrm{HS}$ and $\mathrm{Ob}-\mathrm{N}$. In univariate correlation analyses applied for PwO (Table 3), RERpeak was found positively and significantly correlated with FM, FFM and $\mathrm{VO}_{2} / \mathrm{kg}$ ( $p=0.02, p=0.005, p=0.011$, respectively), but inversely with $G_{\mathrm{AUC}}(p=0.014) . \Delta$ RER was directly and significantly correlated with $\mathrm{FM}(p=0.04)$ and $\mathrm{VO}_{2} / \mathrm{kg}(p=0.024)$, while it inversely correlated with age $(p=0.006)$, HO$\mathrm{MA}_{\mathrm{IR}}(p=0.038)$, FPG $(p=0.048)$, and $G_{\mathrm{AUC}}(p=0.002)$. $\triangle$ RER $\%$ correlated directly with $\mathrm{VO}_{2} / \mathrm{kg}(p=0.048)$, and inversely with age $(p=0.006)$, waist circumference $(p=$ $0.028), G_{\mathrm{AUC}}(p=0.002)$, and $\mathrm{HOMA}_{\mathrm{IR}}(p=0.046)$. In multivariate stepwise regression analyses (Table 4) RERpeak was found independently and directly determined by FFM and inversely by $G_{\text {AUC }}$, while $\triangle$ RER and $\triangle$ RER $\%$ were independently determined by $G_{\mathrm{AUC}}$ only. Also, when excluding $\mathrm{Ob}-\mathrm{T} 2 \mathrm{DM}$ and after adjusting for BMI, $\triangle \mathrm{RER}$, and $\triangle \mathrm{RER} \%$ still remained independently determined by $G_{\mathrm{AUC}}$ only.

\section{Discussion}

The main finding of this study is that people with severe obesity and those with type 2 diabetes (ObT2DM) and prediabetes (Ob-preDM) were found to have a similar, significantly lower, increase in the RER during maximal CPET than those with obesity and normal glucose levels (Ob-N). To the best of our knowledge, this is the first study to analyze the metabolic response during maximal CPET in a large population with a high degree of obesity, evaluated within a standardized clinical setting. This study compares subjects with different metabolic phenotypes, thus providing an overview of a hypothetical continuum from health to disease with increasing metabolic risk. Previous literature already documented that individuals with obesity and various degrees of metabolic alterations had an impaired metabolic flexibility during exercise [23-25]. However, all these studies evaluated submaximal exercise and were performed on small populations, characterized by overweight and/or mild to moderate obesity, providing partially contrasting results. Malin et al. [26] studied a population with overweight/moderate obesity and found that those with both glucose intolerance and fasting hyperglycemia had lower RER during continuous, submaximal exercise. Moreover, Prior et al. [27] described that subjects with glucose intolerance had a 


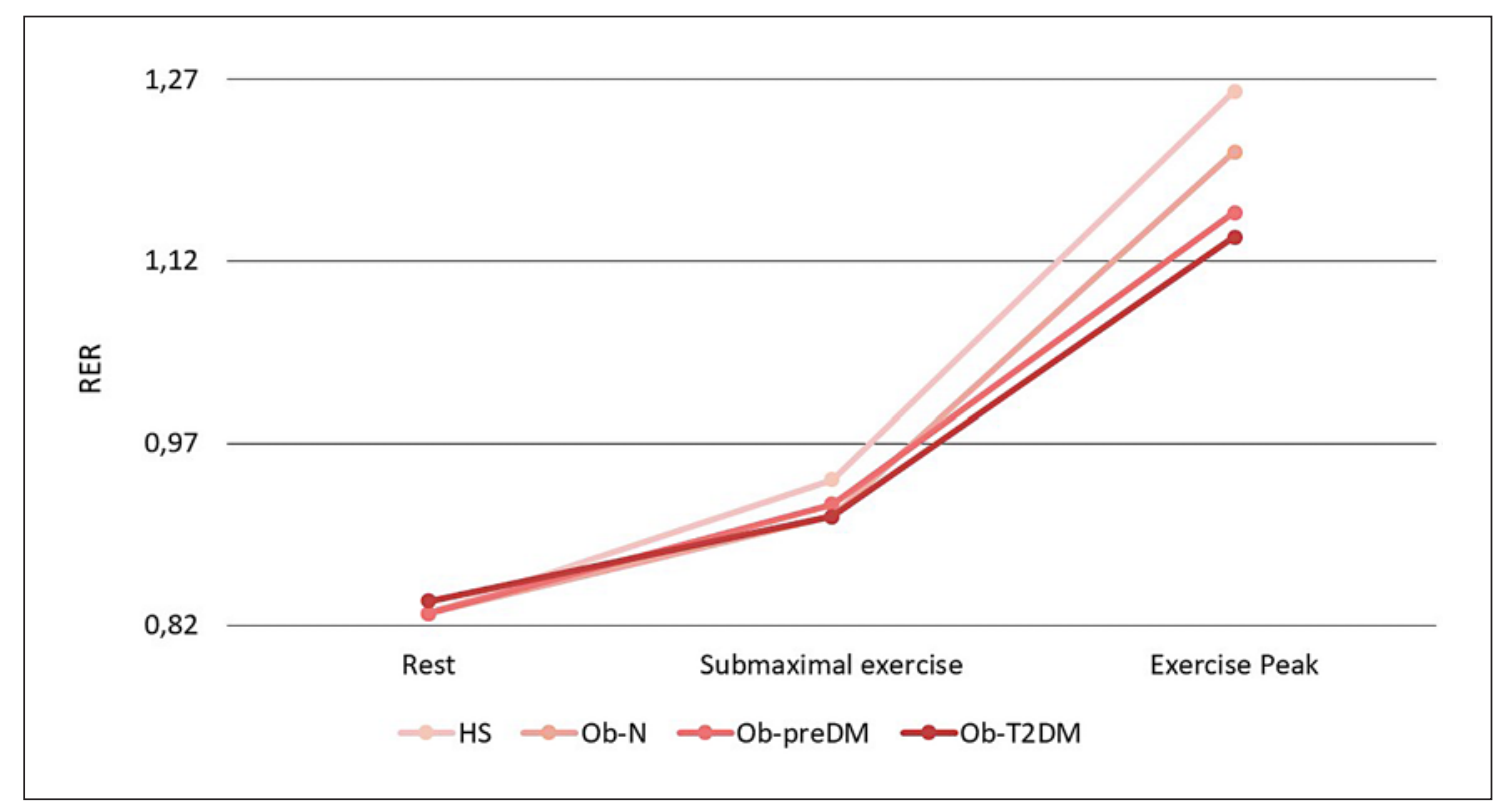

Fig. 1. Metabolic response to exercise in the different subpopulations examined in this study. RER measured at rest, during submaximal exercise, and at peak of exercise. Passing progressively from health to severe obesity, up to obesity complicated by prediabetes or diabetes, the ability to use glucose during exercise seems increasingly impaired. However, in this study population,
Ob-preDM and Ob-T2DM showed comparable metabolic response during exercise. RER, respiratory exchange ratio; HS, healthy subjects; Ob-N, people with obesity and normal glycemic status; Ob-preDM, people with obesity and prediabetes; ObT2DM, people with obesity and type 2 diabetes.

Table 3. Impact of anthropometric and functional parameters on metabolic response to exercise

\begin{tabular}{|c|c|c|c|c|c|c|}
\hline & \multicolumn{2}{|c|}{ RERpeak } & \multicolumn{2}{|l|}{$\triangle \mathrm{RER}$} & \multicolumn{2}{|l|}{$\triangle \mathrm{RER} \%$} \\
\hline & $R$ & $p$ value & $r$ & $p$ value & $r$ & $p$ value \\
\hline Age, years & Ns & & -0.299 & 0.006 & -0.294 & 0.006 \\
\hline BMI, $\mathrm{kg} / \mathrm{m}^{2}$ & Ns & & Ns & & Ns & \\
\hline Waist, cm & Ns & & Ns & & -0.246 & 0.028 \\
\hline $\mathrm{FM}, \mathrm{kg}$ & 0.254 & 0.02 & 0.219 & 0.04 & & Ns \\
\hline FFM, kg & 0.305 & 0.005 & Ns & & Ns & \\
\hline$G_{\mathrm{AUC}} \min , \mathrm{mmol} / \mathrm{L}$ & -0.311 & 0.014 & -0.387 & 0.002 & -0.378 & 0.002 \\
\hline$I_{\mathrm{AUC}} \min , \mathrm{mU} / \mathrm{L}$ & Ns & & Ns & & Ns & \\
\hline $\mathrm{HOMA}_{\mathrm{IR}}$ & Ns & & -0.240 & 0.038 & -0.232 & 0.046 \\
\hline $\mathrm{ISI}_{\mathrm{M}}$ & Ns & & Ns & & Ns & \\
\hline $\mathrm{FPG}, \mathrm{mmol} / \mathrm{L}$ & Ns & & -0.215 & 0.048 & Ns & \\
\hline METs & Ns & & Ns & & Ns & \\
\hline $\mathrm{VO}_{2}, \mathrm{~mL} / \mathrm{min} / \mathrm{kg}$ & 0.276 & 0.011 & 0.244 & 0.024 & 0.216 & 0.048 \\
\hline
\end{tabular}

Univariate correlation analyses, performed for $\mathrm{PwO}$, analyzing the metabolic response to maximal exercise. RERpeak, $\triangle \mathrm{RER}$, and $\triangle \mathrm{RER} \%$ were tested for those parameters that showed significant differences between Ob$\mathrm{N}, \mathrm{Ob}$-preDM, and Ob-T2DM. Correlation is expressed as Pearson's $R$ coefficient; $p$ value is considered significant when $<0.05$. FM, fat mass; FFM, fat free mass; FPG, fasting plasma glucose; $G_{\mathrm{AUC}}$, glucose area under curve; $I_{\mathrm{AUC}}$, insulin area under curve; ISI $_{M}$, insulin sensitivity Matsuda index; METs, peak metabolic equivalent of tasks; RER, respiratory exchange ratio; RERpeak, respiratory exchange ratio at peak of exercise; $\triangle R E R$, RERpeak-RERrest; $\mathrm{PwO}$, people with obesity; $\mathrm{Ob}-\mathrm{N}$, people with obesity and normal glycemic status; Ob-preDM, people with obesity and prediabetes; Ob-T2DM, people with obesity and type 2 diabetes; HOMA $\mathrm{IR}_{\mathrm{I}}$, Homeostasis Model Assessment index. 
Table 4. Multivariate stepwise regression analyses evaluating metabolic response to exercise in PWO

\begin{tabular}{|c|c|c|c|c|c|c|}
\hline & \multicolumn{2}{|c|}{ RERpeak $^{*}$} & \multicolumn{2}{|l|}{$\triangle \mathrm{RER}^{*}$} & \multicolumn{2}{|c|}{$\triangle \mathrm{RER} \% *$} \\
\hline & beta & $p$ value & beta & $p$ value & beta & $p$ value \\
\hline \multicolumn{7}{|l|}{ All PwO } \\
\hline FFM, kg & 0.271 & 0.026 & - & & - & \\
\hline$G_{\mathrm{AUC}} \min , \mathrm{mmol} / \mathrm{L}$ & -0.295 & 0.016 & -0.387 & 0.002 & -0.328 & 0.013 \\
\hline \multicolumn{7}{|l|}{$\mathrm{Ob}-\mathrm{N}$ and $\mathrm{Ob}-\mathrm{preDM}$} \\
\hline FFM, kg & 0.363 & 0.006 & - & & - & \\
\hline$G_{\mathrm{AUC}} \mathrm{min}, \mathrm{mmol} / \mathrm{L}$ & Ns & & -0.307 & 0.020 & -0.309 & 0.019 \\
\hline
\end{tabular}

Multivariate correlation analyses performed for all $\mathrm{PwO}$ and by excluding $\mathrm{Ob}-\mathrm{T} 2 \mathrm{DM}$, evaluating the impact of those parameters that showed significant correlations in univariable analysis (FFM and $G_{\mathrm{AUC}}$ ) on parameters of metabolic response to exercise, that is, RERpeak, $\triangle \mathrm{RER}$, and $\triangle \mathrm{RER} \%$. Correlation is expressed as beta coefficient; $p$ value is considered significant in $<0.05$. FFM, fat free mass; $G_{\mathrm{AUC}}$, glucose area under curve; RER, respiratory exchange ratio; RERpeak, respiratory exchange ratio at peak of exercise; $\triangle$ RER, RERpeak-RERrest; PwO, people with obesity; Ob-T2DM, people with obesity and type 2 diabetes; BMI, body mass index. * Adjusted for BMI.

significant impairment of carbohydrate metabolism during submaximal exercise. They found also that metabolic inflexibility during exercise was related to glucose intolerance [27]. In line with these findings, we found that RERpeak was significantly lower in $\mathrm{Ob}$ preDM and $\mathrm{Ob}-\mathrm{T} 2 \mathrm{DM}$ than $\mathrm{Ob}-\mathrm{N}$ and $\mathrm{HS}$. Indeed, no statistical difference was found between Ob-preDM and $\mathrm{Ob}-\mathrm{T} 2 \mathrm{DM}$, confirming, once again, the high metabolic similarity between prediabetes and type 2 diabetes in $\mathrm{PwO}$ (Fig. 1). The majority of patients with diabetes did not display micro- or macrovascular complications, and most of them had a recent diagnosis of diabetes $(<5$ years), despite not all demonstrated optimal glycemic control. This homogeneous study population allows studying the role of diabetes itself by limiting the potential confounding factors of associated long-term complications. Nevertheless, the metabolic response to exercise is clearly different between $\mathrm{Ob}-\mathrm{N}$ and both $\mathrm{Ob}$ preDM and Ob-T2DM. Moreover, metabolic flexibility seems to be crucial for the metabolic response and substrate selection during exercise. Evidence of such metabolic inflexibility during incremental/maximal exercise implies a number of possible pathophysiological mechanisms $[26,28,29]$. The reduction in metabolic flexibility in individuals with altered fasting glucose has been explained by a selective impairment of insulin-stimulated glucose oxidation and a reduced insulin inhibition of lipid oxidation. This suggests a crucial role of the glucose-fatty acid cycle in regulating the glucose flux, and an impaired regulation of the lipolysis even among pre-diabetic individuals [28]. Furthermore, the dysreg-

Obesity, Diabetes, and Exercise Metabolism ulation in homeostasis of free fatty acids and glucose in prediabetic subjects could lead to ectopic fat distribution $[8,30]$. These elevated levels of plasma free fatty acids [31] can in turn inhibit glycogen synthase and pyruvate dehydrogenase activity, obtaining a lower glucose disposal and a restriction in glucose oxidation for skeletal muscles [32, 33], energetic substrates needed particularly at higher intensities. Indeed, we found that the $G_{\mathrm{AUC}}$ independently correlated with the metabolic response during exercise ( $\triangle \mathrm{RER}$ ), while RERpeak after excluding Ob-T2DM subjects was determined by FFM only. It has been well-described that skeletal muscles, via their insulin independent glucose oxidative capacity during exercise, play a key role in subjects at risk of type 2 diabetes, suggesting the hypothesis that metabolic inflexibility may precede the development of insulin resistance $[34,35]$. Furthermore, it can be assumed that mitochondrial function and metabolic pathways involved in metabolic flexibility may be influenced by physical activity levels [36]. In the present study, the levels of physical activity were not assessed quantitatively, but anamnestic information was collected about the active or sedentary lifestyle. Healthy subjects were defined as such also on the basis of their active lifestyle [37], while $\mathrm{PwO}$ showed a high prevalence of sedentary behavior (80.7\%). Nevertheless, among subgroups of $\mathrm{PwO}$, the prevalence of sedentary habits was similar. Thus, it seems unlikely that this issue could have affected the study outcomes on metabolic differences in our population. Furthermore, the continuous exposure to excess of substrates that occurs in severe obesity re- 
duces metabolic flexibility affecting also mitochondrial oxidative capacity in humans [33]. In particular, mitochondria select the most appropriate energy source for each physiological condition, but in the context of chronic overfeeding, competition between substrates increases and the mitochondria are stuck in a state of indecision (mitochondrial "gridlock"). In this condition, insulin should exert the fundamental role to direct the systemic flux of substrates, but when insulin resistance has been developed, metabolic consequences of the substrate excess are amplified, by unleashing a storm of nutrients that are distributed following abnormal interaction between hormonal and metabolic mechanisms. Thus, metabolic inflexibility can be considered as both a cause and marker of mitochondrial congestion, which in turn influences insulin response and thus cellular glucose uptake [2]. Moreover, it is known that skeletal muscles of subjects with obesity have an increased content of triglycerides and poor glycogen storage inducing the choice of lipids as energy substrate [38-40]. During exercise also, insulin-independent mechanisms are activated, which trigger the translocation of GLUT4 and glucose utilization [41]. This is even more pronounced at vigorous intensity exercise, when glucose is the preferred fuel to sustain effort. Indeed, our data are in line with those of a recent study, where the metabolic response to submaximal exercise was similar when overweight and obese subjects were compared with healthy controls [42]. However, the distinctive metabolic response among subgroups of $\mathrm{PwO}$ became more pronounced at maximal exercise intensities, where glucose is more and more needed as higher efficient energetic substrate (Fig. 1). Although the physiological response to exercise may be influenced by fat distribution [43], in our study, the waist circumference was not independently related to metabolic inflexibility during exercise, and the difference in waist circumference was significant only between $\mathrm{Ob}$ T2DM and Ob-N. Furthermore, it has been previously observed that the physiological response to exercise in patients with obesity and chronic obstructive pulmonary disease was different if performed on a bike and compared to a treadmill [44]. Nevertheless, in the present study, the little percentage of $\mathrm{PwO}$ that performed CPET on a cycle ergometer was similarly distributed among subgroups of $\mathrm{PwO}$ and should thus not significantly affect study outcomes.

Data of our study have also highlighted a significant progressive impairment in functional capacity from HS to those with obesity and comorbidities, while absolute
$\mathrm{VO}_{2}$ peak did not show any significant difference between $\mathrm{PwO}$. These results confirm previous findings and underline the importance of early functional evaluation in these subjects [45]. Future studies might specifically investigate if exercise and other therapeutic/lifestyle interventions could improve metabolic (in)flexibility during exercise. This work pointed out that people with obesity and prediabetes already have functional metabolic changes that characterize those with diabetes. Therefore, more clinical attention should be paid to $\mathrm{PwO}$ and prediabetes. Indeed, metabolic impairment can be unmasked early by CPET, which is of important clinical relevance, allowing a timely and more tailored multidisciplinary intervention. Future investigations should examine the trend of metabolic inflexibility in a prospective experimental design and evaluate the specific impact of the anaerobic metabolism in subjects with different metabolic impairments.

In conclusion, this study shows that people with severe obesity, especially when complicated by prediabetes or diabetes, are characterized by metabolic inflexibility measured by RER during exercise. Moreover, $\triangle$ RER is independently determined by $G_{\text {AUC. }}$. Our findings suggest that in a population with severe obesity, subjects with prediabetes and diabetes present similar metabolic inflexibility. CPET seems indeed useful for an early detection of metabolic inflexibility in this population. This study provided further characterization of an obesity phenotype at higher metabolic risk, aiming to pave the way for subsequent studies that focus on the appropriate diagnostic assessment, therapeutic goals, and timing for treatment.

\section{Statement of Ethics}

The study complied with the guidelines for human studies and was conducted in accordance with the World Medical Association Declaration of Helsinki. All study participants provided their written informed consent to participate in the study. The protocol was approved by the "Padua Ethical Committee for Clinical Research" (2892P, June 10, 2013).

\section{Conflict of Interest Statement}

The authors have no conflicts of interest to declare.

\section{Funding Sources}

This research received no specific grant from any funding agency in the public, commercial, or not-for-profit sectors. 


\section{Author Contributions}

F.B., A.B., D.N., A.G., S.B., G.Q., R.V., L.B., and A.E. contributed to the conception and/or design of the work. F.B., A.B., D.N., A.G., S.B., C.C., R.M., G.Q., M.B., R.V., L.B., and A.E. contributed to the acquisition and/or analysis, and/or interpretation of data for the work. F.B. and A.B. drafted the manuscript. All authors critically revised the manuscript and gave final approval.

\section{Data Availability Statement}

Data that support the findings of this study are available on reasonable request from the corresponding author.

\section{References}

1 Di Angelantonio E, Bhupathiraju SN, Wormser D, Gao P, Kaptoge S, de Gonzalez AB, et al. Body-mass index and all-cause mortality: individual-participant-data meta-analysis of 239 prospective studies in four continents. Lancet. 2016;388(10046):776-86.

2 Muoio DM. Metabolic inflexibility: when mitochondrial indecision leads to metabolic gridlock. Cell. 2014;159(6):1253-62.

3 Timmis A, Townsend N, Gale CP, Torbica A, Lettino M, Petersen SE, et al. European society of cardiology: cardiovascular disease statistics 2019. Eur Heart J. 2020;41(1):12-85.

4 Cosentino F, Grant PJ, Aboyans V, Bailey CJ, Ceriello A, Delgado V, et al. 2019 ESC Guidelines on diabetes, pre-diabetes, and cardiovascular diseases developed in collaboration with the EASD. Eur Heart J. 2020;41(2):255-323.

5 Goodpaster BH, Sparks LM. Metabolic flexibility in health and disease. Cell Metab. 2017; 25(5):1027-36.

6 Kelley DE, Mandarino LJ. Fuel selection in human skeletal muscle in insulin resistance: a reexamination. Diabetes. 2000;49(5):677-83.

7 American Diabetes Association. 2. Classification and diagnosis of diabetes: standards of medical care in diabetes - 2019. Diabetes Care. 2019;42(Suppl 1):S13-28.

8 Belligoli A, Compagnin C, Sanna M, Favaretto F, Fabris R, Busetto L, et al. Characterization of subcutaneous and omental adipose tissue in patients with obesity and with different degrees of glucose impairment. Sci Rep. 2019; 9(1):11333-12.

9 Blair SN, Kohl HW, Barlow CE, Gibbons LW, Paffenbarger RS, Macera CA. Changes in physical fitness and all-cause mortality: a prospective study of healthy and unhealthy men. JAMA. 1995;273(14):1093-8.

10 Guazzi M, Adams V, Conraads V, Halle M, Mezzani A, Vanhees L, et al. EACPR/AHA scientific statement. Clinical recommendations for cardiopulmonary exercise testing data assessment in specific patient populations. Circulation. 2012;126(18):2261-74.

11 Borasio N, Neunhaeuserer D, Gasperetti A, Favero C, Baioccato V, Bergamin M, et al. Ventilatory response at rest and during maximal exercise testing in patients with severe obesity before and after sleeve gastrectomy. Obes Surg. 2021;31:694-701.
12 Kakutani N, Fukushima A, Yokota T, Katayama T, Nambu H, Shirakawa R, et al. Impact of high respiratory exchange ratio during submaximal exercise on adverse clinical outcome in heart failure. Circ J. 2018;82(11):2753-60.

13 Ross R, Blair SN, Arena R, Church TS, Després JP, Franklin BA, et al. Importance of assessing cardiorespiratory fitness in clinical practice: a case for fitness as a clinical vital sign: a scientific statement from the American Heart Association. Circulation. 2016;134(24): e653-99.

14 Williams B, Mancia G, Spiering W, Agabiti Rosei E, Azizi M, Burnier M, et al. 2018 ESC/ ESH Guidelines for the management of arterial hypertension. Eur Heart J. 2018;39(33): 3021-104.

15 Mach F, Baigent C, Catapano AL, Koskinas KC, Casula M, Badimon L, et al. 2019 ESC/ EAS Guidelines for the management of dyslipidaemias: lipid modification to reduce cardiovascular risk. Eur Heart J. 2020;41(1):11188.

16 Sateia MJ. International classification of sleep disorders-third edition: highlights and modifications. Chest. 2014;146(5):1387-94.

17 Matsuda M, DeFronzo RA. Insulin sensitivity indices obtained from oral glucose tolerance testing: comparison with the euglycemic insulin clamp. Diabetes Care. 1999;22(9):146270.

18 Matthews DR, Hosker JR, Rudenski AS, Naylor BA, Treacher DF, Turner RC, et al. Homeostasis model assessment: insulin resistance and B-cell function from fasting plasma glucose and insulin concentrations in man. Diabetologia. 1985;28:412-9.

19 Weir JBV. New metods for calculating metabolic rate with special reference to protein metabolism. J Physiol. 1949;109(1-2):1-9.

20 Janssen I, Heymsfield SB, Baumgartner RN, Ross R. Estimation of skeletal muscle mass by bioelectrical impedance analysis. J Appl Physiol. 2000;89(2):465-71.

21 Neunhaeuserer D, Gasperetti A, Savalla F, Gobbo S, Bullo V, Bergamin M, et al. Functional evaluation in obese patients before and after sleeve gastrectomy. Obes Surg. 2017; 27(12):3230-9.

22 Borg GA. Psychophysical bases of perceived exertion. Med Sci Sports Exerc. 1982;14(5): 377-81.
23 Braun B, Sharoff C, Chipkin SR, Beaudoin F. Effects of insulin resistance on substrate utilization during exercise in overweight women. J Appl Physiol. 2004;97(3):991-7.

24 Goodpaster BH, Wolfe RR, Kelley DE. Effects of obesity on substrate utilization during exercise. Obes Res. 2002;10(7):575-84.

25 Kanaley JA, Weatherup-Dentes MM, Alvarado CR, Whitehead G. Substrate oxidation during acute exercise and with exercise training in lean and obese women. Eur J Appl Physiol. 2001;85(1-2):68-73.

26 Malin SK, Viskochil R, Oliver C, Braun B. Mild fasting hyperglycemia shifts fuel reliance toward fat during exercise in adults with impaired glucose tolerance. J Appl Physiol. 2013; 115(1):78-83.

27 Prior SJ, Ryan AS, Stevenson TG, Goldberg AP. Metabolic inflexibility during submaximal aerobic exercise is associated with glucose intolerance in obese older adults. Obesity. 2014;22(2):451-7.

28 Færch K, Vaag A. Metabolic inflexibility is a common feature of impaired fasting glycaemia and impaired glucose tolerance. Acta Diabetol. 2011;48(4):349-53.

29 Horowitz JF, Klein S. Oxidation of nonplasma fatty acids during exercise is increased in women with abdominal obesity. J Appl Physiol. 2000;89(6):2276-82.

30 Smith U. Abdominal obesity: a marker of ectopic fat accumulation. J Clin Invest. 2015; 125(5):1790-2.

31 Aucouturier J, Duché P, Timmons BW. Metabolic flexibility and obesity in children and youth. Obes Rev. 2011;12(501):e44-53.

32 Boyle KE, Friedman JE, Janssen RC, Underkofler C, Houmard JA, Rasouli N. Metabolic inflexibility with obesity and the effects of fenofibrate on skeletal muscle fatty acid oxidation. Horm Metab Res. 2017;49(1):50-7.

33 Smith RL, Soeters MR, Wüst RCI, Houtkooper RH. Metabolic flexibility as an adaptation to energy resources and requirements in health and disease. Endocr Rev. 2018;39(4): 489-517.

34 Barazzoni R, Bischoff S, Boirie Y, Busetto L, Cederholm T, Dicker D, et al. Sarcopenic obesity: time to meet the challenge. Obes Facts. 2018;11:294-305. 
35 Galgani JE, Moro C, Ravussin E. Metabolic flexibility and insulin resistance. Am J Physiol Endocrinol Metab. 2008;295(5):E1009-17.

36 Bergouignan A, Antoun E, Momken I, Schoeller DA, Gauquelin-Koch G, Simon C, et al. Effect of contrasted levels of habitual physical activity on metabolic flexibility. J Appl Physiol. 2013;114(3):371-9.

37 Sallis RE, Baggish AL, Franklin BA, Whitehead JR. The call for a physical activity vital sign in clinical practice. Am J Med. 2016; 129(9):903-5.

38 Kelley DE, Simon B, Janosky J. Skeletal muscle density : effects of obesity diabetes mellitus. Am J Clin Nutr. 1991;54(3):509-15.
39 Callahan ZJ, Oxendine MJ, Schaeffer PJ. Intramuscular triglyceride content precedes impaired glucose metabolism, without evidence for mitochondrial dysfunction during early development of a diabetic phenotype. Appl Physiol Nutr Metab. 2017;42:963-72.

40 Højlund K, Birk JB, Klein DK, Levin K, Rose AJ, Hansen BF, et al. Dysregulation of glycogen synthase $\mathrm{COOH}$ - and $\mathrm{NH} 2$-terminal phosphorylation by insulin in obesity and type 2 diabetes mellitus. J Clin Endocrinol Metab. 2009;94(11):4547-56.

41 Jessen N, Goodyear LJ. Invited review: contraction signaling to glucose transport in skeletal muscle. J Appl Physiol. 2005;99(1):330-7.

42 Gar C, Rottenkolber M, Haenelt M, Potzel AL, Kern-Matschilles S, Then C, et al. Altered metabolic and hormonal responses to moderate exercise in overweight/obesity. Metabolism. 2020;107:154219.
43 Li J, Li S, Feuers RJ, Buffington CK, Cowan GS. Influence of body fat distribution on oxygen uptake and pulmonary performance in morbidly obese females during exercise. Respirology. 2001;6(1):9-13.

44 Ciavaglia CE, Guenette JA, Ora J, Webb KA, Neder JA, O'Donnell DE. Does exercise test modality influence dyspnoea perception in obese patients with COPD? Eur Respir J. 2014;43(6):1621-30.

45 Neunhaeuserer D, Savalla F, Gasperetti A, Rami A, Gobbo S, Campi C, et al. Cardiorespiratory function and $\mathrm{VO} 2$ kinetics after sleeve gastrectomy: a follow-up analysis. Intern Emerg Med. 2020;15(7):1201-5. 